\title{
Interdecadal changes in the precipitation seasonal cycle over Southern South America and their relationship with surface temperature
}

\author{
Matilde Rusticucci*, Olga Penalba
}

Departamento de Ciencias de la Atmósfera y los Océanos, Universidad de Buenos Aires, Ciudad Universitaria-Pab. II, 1428 Buenos Aires, Argentina

\begin{abstract}
The decadal variability in the structure of the annual precipitation cycle over Southern South America (SSA) is analysed with the purpose of investigating whether the lower frequency variability laid bare by annual data is also evident in the annual precipitation structure. Climatic analysis shows that the annual cycle plus the semi-annual cycle dominate the annual variability of precipitation in SSA and represent most of the physical factors responsible for the observed patterns. The percentage of variance explained by the annual cycle shows 2 local maxima, in northwestern Argentina and southern Chile, with opposite phases, summer and winter. The interdecadal analysis of the annual cycle shows 2 areas of relevant variability: one over the central east and the other over the north east. In the first area, there is a positive trend in the variance explained by the first harmonic, indicating that precipitation tends to be better represented by an annual cycle, a fact that might indicate a climatic change in so far as this variable is concerned. In view of global warming, and as a first step towards quantifying the relationship between temperature and precipitation in the region, correlation coefficients are evaluated. The correlation structure of the warmer period 1943-52 generally shows a slight correlation pattern when compared to the 2 colder periods, 1955-64 and 1966-75. In northwestern Argentina, the highest positive correlation coefficients are found at the coldest times in 1955-64, and are probably related to an increase in cloudiness. During summer months (November to February), there is an inverse relationship between precipitation and temperature over most of SSA. That is, warmer/colder summers are associated with precipitation below/above the mean. In autumn and spring months, the correlation is positive in the eastern part of Argentina and Paraguay, and represents well the mechanism of maximum precipitation in this area, which is mainly the result of cyclogenesis. Winter correlation shows a weak positive pattern over SSA and a negative correlation area to the east of the Cordillera de los Andes, which is more intense in spring.
\end{abstract}

KEY WORDS: Precipitation · Seasonal cycle $\cdot$ Decadal $\cdot$ Temperature $\cdot$ Southern South America

\section{INTRODUCTION}

Precipitation over Southern South America (SSA) is governed by a number of physical, spatial and temporal factors. The landmass lies between the Pacific and Atlantic oceans, and is crossed in the north-south direction by the Cordillera de los Andes, a high and narrow mountain range (maximum height: $6959 \mathrm{~m}$ ). The Andes separate the main Pacific Semipermanent Anticyclone flow, to the west, from the Atlantic Semipermanent Anticyclone, to the east of SSA.

*E-mail:mati@at1.fcen.uba.ar
Regional precipitation is determined by the peculiarities associated with prevailing topographical and atmospheric conditions. The complexity of precipitation regimes is of undeniable climatological interest, but an understanding of their characteristic features also has economic and agricultural relevance. The main purpose of this paper is to analyse the interdecadal variability of precipitation and its possible relationship with temperature variability, which is an important subject in climate forecasting.

Van Loon et al. (1993) and Hurrell \& van Loon (1994) pioneered the study of interdecadal variations in the annual cycle of the southern hemisphere atmospheric 
circulation. More recently, Chen \& Yen (1997) concluded that interdecadal changes in the southern hemisphere circulation may exhibit different spatial structures during different seasons, with major interdecadal variations occurring in mid and high latitudes. The relevance of interdecadal variation is such that in a paper by Cayan et al. (1998), for example, the authors concluded that decadal variations of precipitation over western North America account for 20 to $50 \%$ of the variance in annual precipitation.

Concerning the precipitation regime over Argentina and its variability, the first work on seasonal precipitation regimes was Prohaska's (1952) paper. In that study, regions having different types of precipitation were classified according to the atmospheric circulation that determines them. Vargas \& Penalba (1985, 1986) studied mean monthly precipitation stability and urban influence on this regime. In general, they showed that the anthropogenic effect produced by the urban areas is not significant, and that series have been stable since 1890 in the province of Buenos Aires (eastern region of central Argentina), even though they have been increasing in recent years. Krepper et al. (1989) analysed the temporal and spatial variability over the central and eastern regions. They identified areas of maximum variability, but they did not focus on a specific season. Castañeda \& Barros (1994) showed that there were significant positive annual precipitation trends in eastern Argentina, in the period 1916-91. Penalba \& Vargas (1996) found that annual precipitation showed significant positive trends at most stations of central-eastern Argentina during the 1890-1980 period. When studying the behaviour of monthly rainfall, a positive trend in precipitation appears, generally in the month of maximum precipitation in the region, January and October. Studying precipitation over Argentina and Chile, Minetti \& Vargas (1997) found 2 climate shifts in annual precipitation between 1930 and 1960, entailing desertification in Argentina and a negative trend in the annual precipitation over Chile

More recently, Hoffmann et al. (1997) analysed the decadal variation of temperature, precipitation and humidity, looking for evidence of possible warming over Argentina. Comparing the periods 1941-50 and 1981-90, they found a considerable temperature increase in the latter decade in different regions of Argentina. Minetti \& Vargas (1983) found a relative cooling of the South-American continent south of $10^{\circ} \mathrm{S}$ especially in the 1951-60 decade with respect to adjacent decades.

Harmonic analysis is a particularly useful tool for studying precipitation patterns, since it offers insight into the spatial variation of different precipitation regimes and highlights the boundaries between them
(Kirkyla \& Hameed 1989). Scott \& Shulman (1979) applied this methodology to examine precipitation over the United States, whereas Finkelstein \& Truppi (1991) applied it to temperature. The global distribution of the annual and semi-annual cycles of precipitation has been examined by Hsu \& Wallace (1976), who studied global precipitation through harmonic analysis applied to climatological data, although considering only a few stations over SSA. Penalba \& Vargas (1996) used this methodology to examine temporal and spatial variations of annual and monthly extreme precipitation in a smaller region with a dense network of stations. They found that the driest years are dominated by a strong annual cycle, whilst the wettest ones are represented by a semi-annual cycle (i.e., reduced seasonality).

Regarding the relationship between monthly precipitation and temperature regime, reference may be made to the work of Zhao \& Khalil (1993), who studied the relationship between these 2 variables over the contiguous United States, by examining the correlation between them. Over most of the United States summer precipitation and temperature tend to be negatively correlated, with positive correlation mainly occurring in winter in some areas. Power et al. (1999) found an out-of-phase relationship between decadal variability in rainfall and decadal variability in temperature in Australia; Pittock (1980a,b) analysed by means of principal component analysis the spatial patterns of yearto-year monthly temperature and precipitation values in the period 1931-60 over SSA, and their relationship with the variation of atmospheric circulation. Three dominant patterns of year-to-year variability were revealed, accounting for $40 \%$ of the variance.

The purpose of this paper is 2-fold: First, to analyse the decadal variability of the precipitation regime with the objective of determining whether the low-frequency variability laid bare by annual data is also evident in the annual precipitation regime. Therefore, the annual cycle and its features and characteristics are studied. Second, in order to attain some understanding about the relationship between monthly precipitation and temperature regimes, the correlation is closely examined.

\section{AVAILABLE DATA AND ANALYSIS TECHNIQUES}

Station data of monthly total precipitation and monthly mean temperature employed in this analysis were taken from the Global Climatology Data Network, Carbon Dioxide Information Analysis Centre, Oak Ridge, Tennessee. This dataset was pre-processed to obtain a network of stations with consistent and 
homogeneous records; in order to obtain stable and representative statistical results almost 60 stations with a minimum record length of $50 \mathrm{yr}$ were chosen. There are a few stations which started in 1901, whose records are affected neither by changes of location and instrumentation, nearby construction of buildings and growth of vegetation nor by an urban heat island effect. In Uruguay, there is only 1 station covering the whole record; the remaining ones in that country have been operative only since the 1950s. The locations of the stations are shown in Fig. 1, and their names, latitude, longitude and length of record are given in Table 1.

Monthly precipitation values for the stations were averaged either: (1) over the total length of the record or (2) over the decades, starting in 1901-10. These series of 12 monthly values were then subjected to harmonic analysis in order to study the climatological pattern of precipitation seasonality and interdecadal variability.

To analyse statistical significance, a

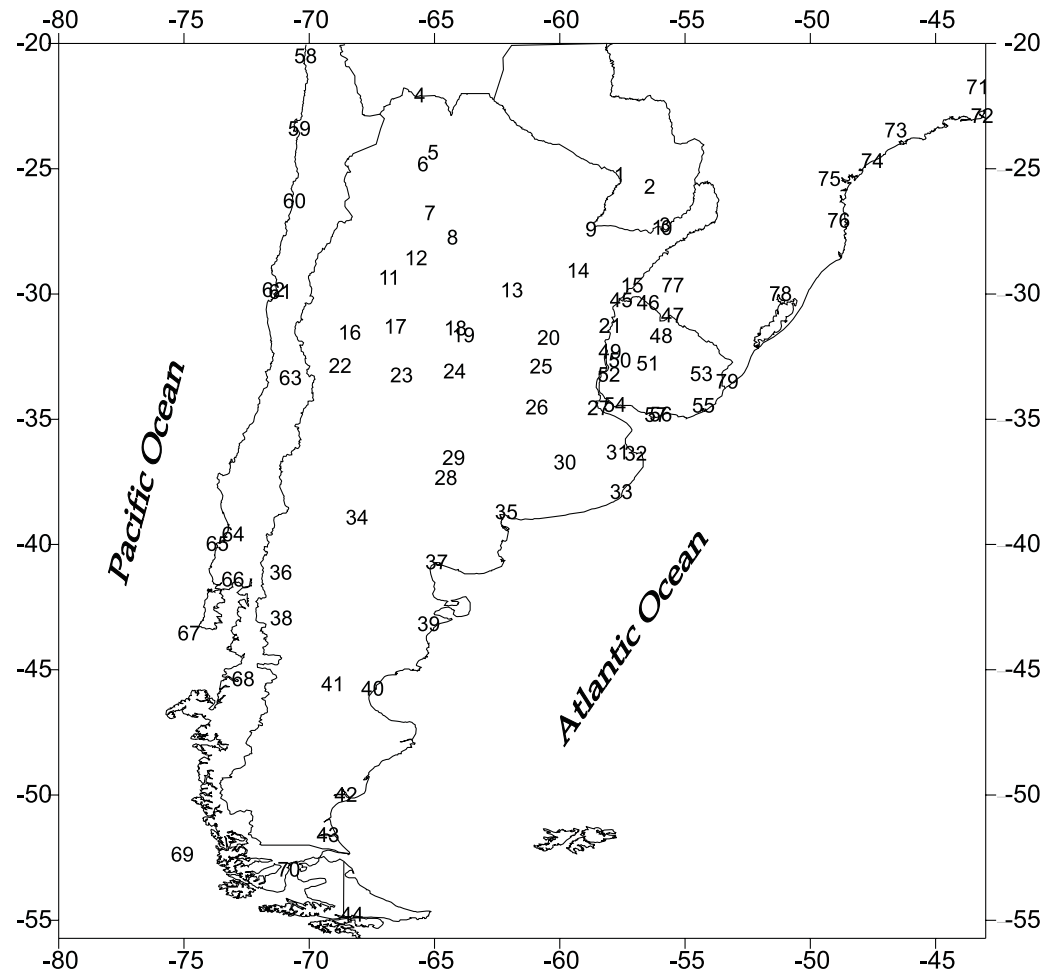

Fig. 1. The stations in Southern South America used in this study test suggested by Siegel (1980) was applied that compares the variance percentage explained by each harmonic with the percentages explained by the remaining harmonics. In this case, a variance percentage above approximately $66 \%$ may be considered significant.

Correlation coefficients between monthly precipitation and temperature were calculated for each month over the whole period, and for each decade over all months. This spatial variability of the precipitationtemperature relationship is illustrated with contour maps. Temporal series were previously subjected to a detrend analysis so as to calculate the correlation coefficients without the effect of trend. The linear trend of each monthly variable (temperature and precipitation) for each station was tested with a $95 \%$ significance level and then the variable was detrended. Missing data were taken into account in 2 different ways: when just a few consecutive data were missing, the analysis of trend was carried out over the entire period (from the first to the last decade); otherwise, the test was applied to each period separately.

Results are reported as follows: (1) the analysis of the precipitation regime obtained for the entire period is given; (2) the interdecadal variability of this precipitation regime is analysed; and (3) the relationship between the regimes of precipitation and temperature is discussed.

\section{RESULTS}

\subsection{Mean precipitation regime (1901-90)}

The region under study is basically characterized by 4 areas having different precipitation regimes. (Hoffmann 1975). Fig. 2 shows the climatological monthly precipitation of 4 stations that represent such different regimes in SSA. Posadas (indicated in Fig. 1 as Stn 10), is representative of the annual precipitation type characterizing the northeast area of the region under study: it shows 2 equinoxial maxima and abundant rainfall throughout the whole year. To the west, Tucumán (Stn 7) is representative of stations located in central and north-northwest SSA, having summer precipitation and strong seasonal variation. Windward of the Andes, around $35^{\circ} \mathrm{S}$, the region shows a winter precipitation regime derived from synoptic systems that may reach those latitudes in that season (Valdivia, Stn 64). Finally, the annual cycle of precipitation at Trelew (Stn 39) is characteristic of the south of SSA, leeward of the Andes (Patagonia), with scarce rainfall throughout the year.

When studying the annual precipitation regime, the primary interest is to determine which are the cycles modulating monthly mean precipitation. With this pur- 
Table 1. Numbers, names, locations and periods of coverage of the stations shown in Fig. 1

\begin{tabular}{|c|c|c|c|c|c|c|c|c|c|}
\hline Number & Name & $\begin{array}{l}\text { Longitude } \\
\qquad\left({ }^{\circ} \mathrm{W}\right)\end{array}$ & $\begin{array}{l}\text { Latitude } \\
\left({ }^{\circ} \mathrm{S}\right)\end{array}$ & Period & Number & Name & $\begin{array}{l}\text { Longitude } \\
\qquad\left({ }^{\circ} \mathrm{W}\right)\end{array}$ & $\begin{array}{c}\text { Latitude } \\
\left({ }^{\circ} \mathrm{S}\right)\end{array}$ & Period \\
\hline 1 & Asunción A. & 57.63 & 25.27 & $1960-90$ & 41 & Sarmiento Arg. & 69.10 & 45.60 & $1903-64$ \\
\hline 2 & Villarrica & 56.43 & 25.75 & $1901-90$ & 42 & Santa Cruz A. & 68.57 & 50.02 & $1903-90$ \\
\hline 3 & Encarnación & 55.83 & 27.32 & $1941-90$ & 43 & Río Gallegos A. & 69.28 & 51.62 & $1931-90$ \\
\hline 4 & La Quiaca & 65.60 & 22.10 & $1903-90$ & 44 & Ushuaia B.A. & 68.32 & 54.80 & $1901-90$ \\
\hline 5 & Jujuy A. & 65.08 & 24.38 & $1931-90$ & 45 & Bella Unión & 57.58 & 30.27 & $1951-90$ \\
\hline 6 & Salta A. & 65.48 & 24.85 & $1901-90$ & 46 & Artigas & 56.50 & 30.38 & $1951-90$ \\
\hline 7 & Tucumán O. & 65.20 & 26.80 & $1901-76$ & 47 & Rivera & 55.53 & 30.88 & $1951-90$ \\
\hline 8 & San. Estero A. & 64.30 & 27.77 & $1901-90$ & 48 & Tacuarembó & 55.98 & 31.70 & $1951-90$ \\
\hline 9 & Corrientes A. & 58.77 & 27.45 & $1901-90$ & 49 & Paysandú & 58.03 & 32.33 & $1951-90$ \\
\hline 10 & Posadas A. & 55.97 & 27.37 & $1903-90$ & 50 & Young & 57.63 & 32.68 & $1951-90$ \\
\hline 11 & La Rioja A. & 66.82 & 29.38 & $1931-90$ & 51 & Paso Los Toros & 56.52 & 32.80 & 1951-90 \\
\hline 12 & Catamarca A. & 65.77 & 28.60 & $1903-90$ & 52 & Mercedes & 58.07 & 33.25 & 1951-90 \\
\hline 13 & Ceres & 61.95 & 29.88 & $1931-90$ & 53 & Treinta y Tres & 54.38 & 33.22 & $1951-90$ \\
\hline 14 & Goya & 59.30 & 29.10 & $1901-90$ & 54 & Colonia & 57.83 & 34.45 & $1951-90$ \\
\hline 15 & Paso Libres A. & 57.15 & 29.68 & $1931-90$ & 55 & Rocha & 54.30 & 34.48 & $1951-90$ \\
\hline 16 & San Juan A. & 68.42 & 31.57 & $1901-90$ & 56 & Carrasco & 56.00 & 34.83 & $1961-90$ \\
\hline 17 & Chepes & 66.60 & 31.33 & $1931-90$ & 57 & El Prado & 56.20 & 34.85 & $1901-88$ \\
\hline 18 & Córdoba & 64.20 & 31.40 & $1951-90$ & 58 & Iquique & 70.18 & 20.53 & $1901-86$ \\
\hline 19 & Pilar O. & 63.88 & 31.67 & $1931-90$ & 59 & Antofagasta & 70.43 & 23.43 & $1931-89$ \\
\hline 20 & Paraná A. & 60.48 & 31.78 & $1901-90$ & 60 & Chanaral & 70.62 & 26.32 & $1931-84$ \\
\hline 21 & Concordia A. & 58.02 & 31.30 & $1902-90$ & 61 & La Serena & 71.20 & 29.90 & $1901-89$ \\
\hline 22 & Mendoza O. & 68.80 & 32.90 & $1901-89$ & 62 & Punta Tortuga & 71.40 & 29.90 & $1901-60$ \\
\hline 23 & San Luis A. & 66.35 & 33.27 & $1931-90$ & 63 & Pudahuel & 70.78 & 33.38 & 1901-90 \\
\hline 24 & Rio Cuarto A. & 64.23 & 33.12 & $1931-90$ & 64 & Valdivia & 73.07 & 39.62 & $1901-90$ \\
\hline 25 & Rosario A. & 60.78 & 32.92 & $1901-89$ & 65 & Punta Galera & 73.70 & 40.00 & $1901-60$ \\
\hline 26 & Junín A. & 60.95 & 34.55 & $1931-90$ & 66 & Puerto Montt & 73.08 & 41.42 & $1901-90$ \\
\hline 27 & O.C. Bs Aires & 58.48 & 34.58 & $1901-89$ & 67 & Is Huafo & 74.83 & 43.57 & $1908-89$ \\
\hline 28 & General Acha & 64.58 & 37.37 & $1901-89$ & 68 & Puerto Aysen & 72.67 & 45.40 & $1931-90$ \\
\hline 29 & Santa Rosa A. & 64.27 & 36.57 & $1941-90$ & 69 & Is Evangelistas & 75.10 & 52.40 & $1901-89$ \\
\hline 30 & Azul A. & 59.83 & 36.75 & $1931-90$ & 70 & Punta Arenas & 70.85 & 53.00 & $1901-90$ \\
\hline 31 & Dolores A. & 57.73 & 36.35 & $1931-90$ & 71 & Juiz de Fora & 43.35 & 21.77 & $1910-90$ \\
\hline 32 & Ajo-Gral Lavalle & le 57.00 & 36.40 & $1901-50$ & 72 & Río de Janeiro & 43.17 & 22.92 & $1901-90$ \\
\hline 33 & Mar Plata A. & 57.58 & 37.93 & $1901-90$ & 73 & Sao Paulo & 46.62 & 23.50 & $1961-90$ \\
\hline 34 & Neuquén A. & 68.13 & 38.95 & $1901-89$ & 74 & Iguapé & 47.55 & 24.72 & $1901-88$ \\
\hline 35 & Bahía Blanca A. & 62.17 & 38.73 & $1901-90$ & 75 & Curitiba & 49.27 & 25.43 & $1901-90$ \\
\hline 36 & Bariloche A. & 71.17 & 41.15 & $1931-90$ & 76 & Brusque & 48.90 & 27.10 & $1906-60$ \\
\hline 37 & S. Antonio O. A. & 64.95 & 40.73 & $1931-90$ & 77 & Alegrete & 55.52 & 29.68 & $1961-88$ \\
\hline 38 & Esquel A. & 71.15 & 42.97 & $1901-90$ & 78 & Porto Alegre & 51.22 & 30.02 & $1961-90$ \\
\hline 39 & Trelew A. & 65.27 & 43.20 & $1901-90$ & 79 & St. Vit. do Palma & a 53.35 & 33.52 & $1961-90$ \\
\hline 40 & C. Rivadavia A. & 67.50 & 45.78 & $1931-90$ & & & & & \\
\hline
\end{tabular}

pose, harmonic analysis was applied to climatological monthly precipitation. The annual and semi-annual cycles represent most of the physical factors responsible for the observed seasonal patterns. The explained variance (a), amplitude (b), and phase (c) corresponding to the annual harmonic can be seen in Fig. 3. The shaded region in Fig. 3a shows the stations for which the variance explained by the annual harmonic is significant at or above the $95 \%$ confidence level. For the entire period, at most stations, the only single significant harmonic is the first one. The percentage of variance explained by the annual cycle shows 2 local maxima. One maximum is located over northwestern Argentina, and the other over southern Chile between 35 and $45^{\circ} \mathrm{S}$. In this latter region, the analysis shows a maximum in the 1 amplitude of the first harmonic (close to $120 \mathrm{~mm}$; Fig. 3b), which represents the second continental precipitation maximum. Both centres have opposite phases (Fig. 3c), the former representing the summer precipitation regime, with storms (see Tucumán, Fig. 2), and the latter representing the winter regime over Chile, in the westerlies region (Valdivia, Fig. 2).

In general, the importance of the annual harmonic decreases towards the eastern coast, where the semiannual cycle becomes important. There are 2 regions of minimum variance explained by the annual harmonic, located in areas where it does not fit well to the climatic rainfall data. One region is located over southern Argentina (south to $40^{\circ} \mathrm{S}$, Patagonia). This is an 

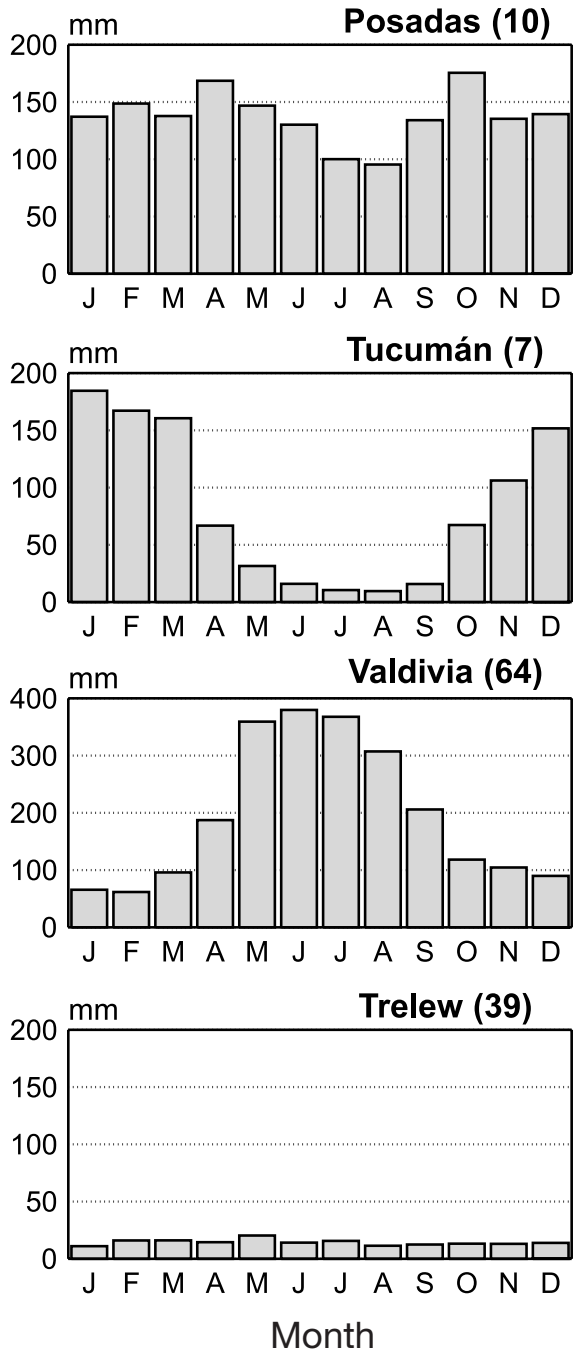

Fig. 2. Climatological monthly precipitation (mm) at 4 stations that represent the region's climate. Notice that the precipitation scale at Valdivia is the double that used for the remaining stations arid region with very low precipitation during the whole year (see Trelew in Fig. 2). The other region is located over Uruguay, northeastern Argentina and southeastern Brazil. It possesses the opposite characteristics, that is, abundant rainfall throughout the year without a dry season (represented by Posadas, Fig. 2).

The map of variance explained by the semi-annual harmonic is shown in Fig. 4. Maxima in variance percentage explained by the second harmonic are less relevant than those explained by the first harmonic, so much so that the test does not indicate them as significant, even though they substantially modify the form of the annual precipitation. The semi-annual cycle of precipitation has 2 centres, located where the annual harmonic is not significant. The most intense centre is located over eastern Uruguay, and the other one over southern Argentina, at approximately $50^{\circ} \mathrm{S}$. The former generates a significant east-west gradient in variance percentage. This spatial pattern in the semiannual harmonic over Uruguay is in perfect agreement with the temporal series of the first eigenvector in climatological monthly rainfalls (Diaz et al. 1998). The rainfall distribution in the course of the year has a first maximum during autumn. In addition, there is a prevailing circulation derived from the semi-permanent Atlantic anticyclone and air masses having their origin in tropical areas. Thus, the Autumn peak in the region can be considered as the result of the convergence of 2 rain-producing circumstances: warming and the advection of humidity (Prohaska 1976); this was also suggested by Compagnucci \& Salles (1997).

Some points stand out when harmonics are analysed in pairs, following the test suggested by Siegel (1980). The region where the variance explained by the first harmonic is maximum, located over northwestern Argentina, has an annual harmonic amplitude greater
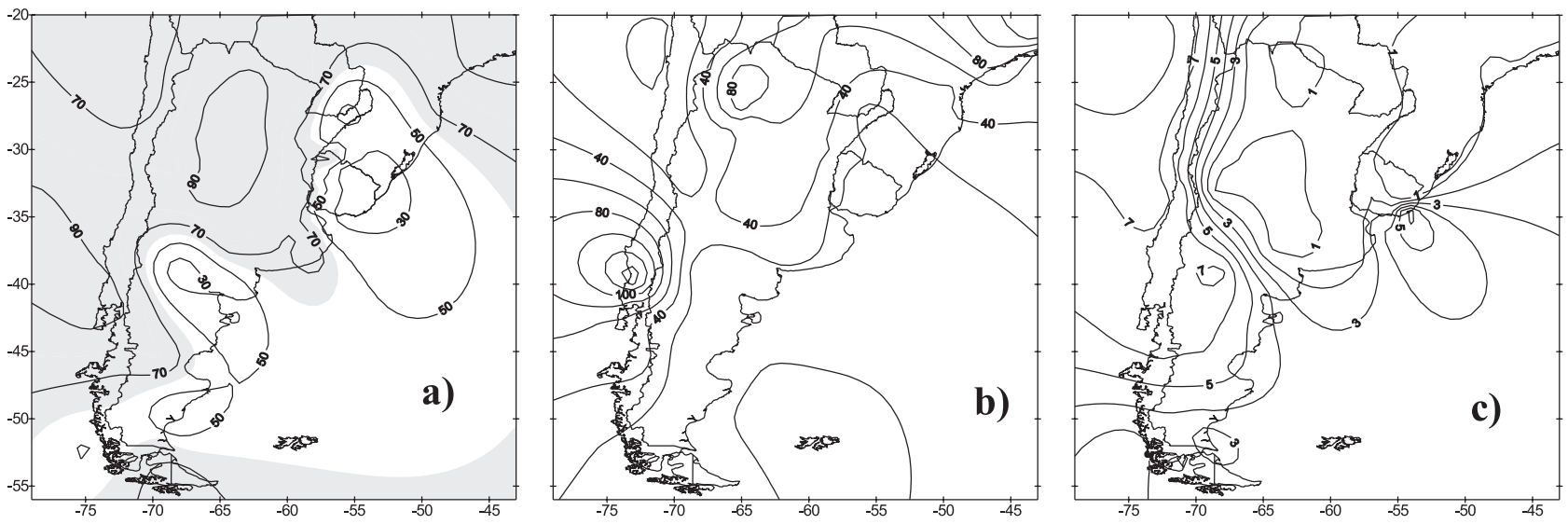

Fig. 3. (a) Explained variance (\%), (b) amplitude (in millimetres) and (c) phase (by month of the year: January = 1) of the annual wave (first harmonic) of precipitation calculated over the climatic period 1901-1990 (except Uruguay, for which the period is 1951-90). In (a) the $95 \%$ significant region is shaded 


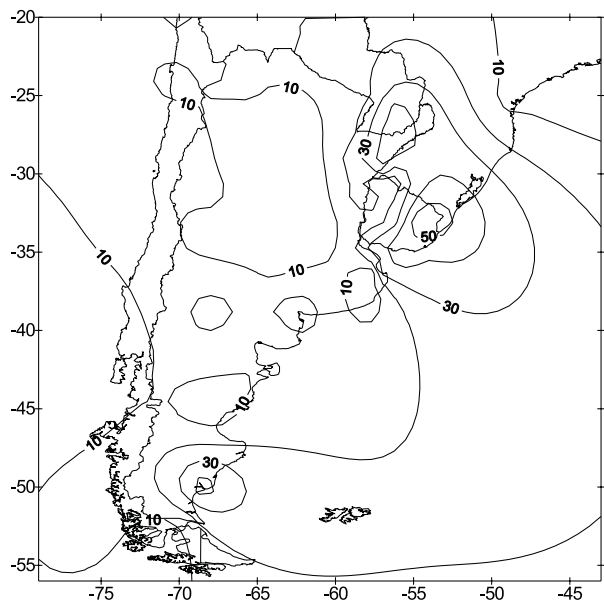

Fig. 4. Variance (\%) explained by the semi-annual wave (second harmonic) for the climatic period 1901-90 for all stations (except Uruguay, for which the period is 1951-90)

than monthly mean precipitation, on account of an extreme summer precipitation regime. La Quiaca (Stn 4) and Salta (Stn 6), with a tropical climate, are located within this centre. In this region, in some cases the precipitation accumulated during the summer accounts for $70 \%$ of the annual precipitation (Poblete et al. 1989). This extreme summer precipitation regime produces a significant first-second pair due to the fact that the annual and semi-annual cycles tend to be 'phase locked' (Hsu \& Wallace 1976), and the second harmonic exists because of the constraint preventing negative precipitation during the dry season. The same conditions may be observed in Córdoba (Stn 18), with a first-third significant pair. Other similar cases are the stations located in central Chile. In this region, precipitation mainly occurs in winter, but a first-second statistically significant pair represents the climatic annual regime. In this case, the result is due to the strong annual cycle, with a small percentage of variance explained by the second harmonic; thus when the 2 harmonics are combined the test shows significance. These results show that the annual variability of precipitation in SSA is dominated by the annual cycle and that, even if in some situations it shows 2 peaks in the annual precipitation regime, the second harmonic alone is not significant, at least in regard to precipitation.

\subsection{Decadal precipitation variability}

In order to determine interdecadal regime variability, harmonic analysis was performed for each decade. The line of $50 \%$ of variance explained by the annual harmonic (bold in Fig. 5) might be considered as the transition zone between 2 different precipitation re- gimes (if the first harmonic is more relevant than the remaining ones or vice versa). Most decades resemble the long-term average, but there are some examples which show interesting changes. Even though station density increases over the decades, it is not the cause of observable changes. Station distribution over the first decades is spatially homogeneous and it is permanent over time, as may be seen in Fig. 5, where stations considered for each decade are indicated.

Over the decades, 'annually shaped' precipitation centres are always located over the same region but the area covered by them is different. The maximum of $90 \%$ explained variance, located over northwestern Argentina, has been enhanced and enlarged into a tongue-like extreme to the southeast over the decades. The annual cycle becomes more important at stations located at central-eastern SSA ( 32 to $38^{\circ} \mathrm{S}, 56$ to $65^{\circ} \mathrm{W}$ ) and has less explained variance at stations to the northeast of Argentina (around $27^{\circ} \mathrm{S}, 57^{\circ} \mathrm{W}$ ). In these regions, the precipitation regime has changed significantly over recent decades. According to the works previously mentioned, in central-eastern SSA, monthly rainfall shows positive trends during maximum precipitation months (from December to March) in the 1956-91 period, and this fact is clearly reflected by the above-mentioned change in the annual cycle. Similarly, over northeastern Argentina, positive trends in monthly rainfall may be observed from April to July, which lead to an amplitude decrease of the annual cycle.

To summarise this interdecadal variability, the relevance of the annual harmonics for each decade was analysed. Three groups of different characteristics were found throughout the whole period under study: (1) stations where the variance explained by the annual cycle is always significant, (2) stations where the annual cycle is never significant, and (3) stations with high decadal variability, where the significance of the annual cycle alternates over the decades (see map in Fig. 6). The current analysis shows that type-1 stations are located within the regions of maximum annual percent explained variance in the entire period; that type- 2 stations are located in regions where neither the variance explained by the first harmonic nor the variance explained by the first and second harmonics are significant; and that type-3 stations are located in climate transition regions: over Patagonia, with the minimum amount of precipitation, and over Mesopotamia $\left(27\right.$ to $35^{\circ} \mathrm{S}, 58$ to $\left.62^{\circ} \mathrm{W}\right)$, with precipitation increasing over the decades.

We have selected some stations to show how the precipitation regime changes over the decades (Fig. 6). The relevance of the first, second and third harmonic is analysed in these cases and compared to the mean annual precipitation in each decade. 
Among the type-1 stations, the stations first analysed are those located over Chile, at the centre of maximum variance explained by the first harmonic. Although annual precipitations at all Chilean stations show sig- nificant negative trends over a longer period that includes the one herein studied (Minetti \& Vargas 1997), this is not true for the period under study itself. For example, Pudahuel, located to the north of the
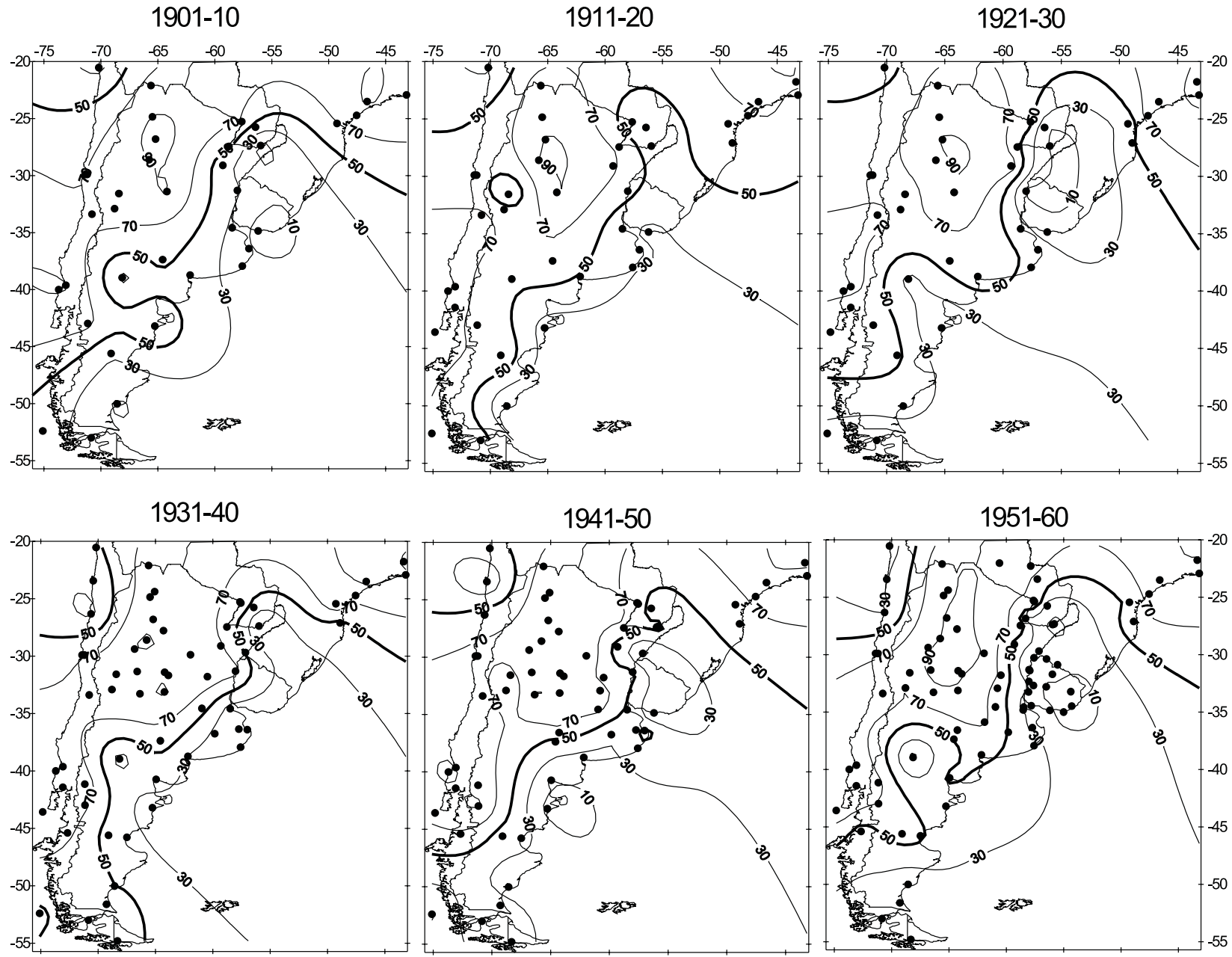

1961-70

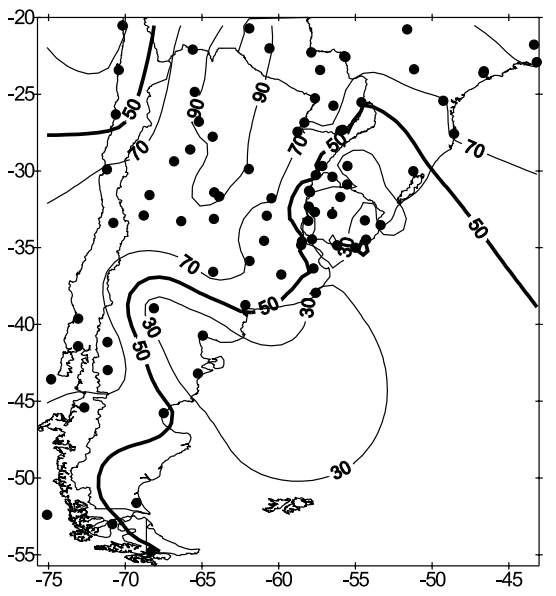

$1971-80$

$1981-90$
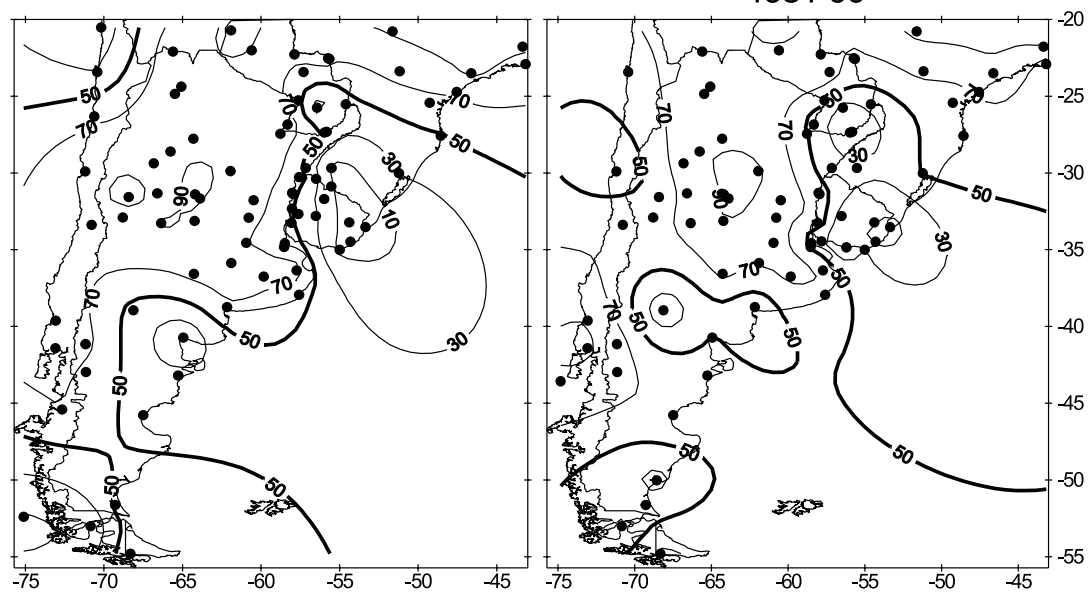

Fig. 5. Decadal annual wave explained variance (\%). Bold line: $50 \%$ of explained variance. (•) Stations used in each decade 


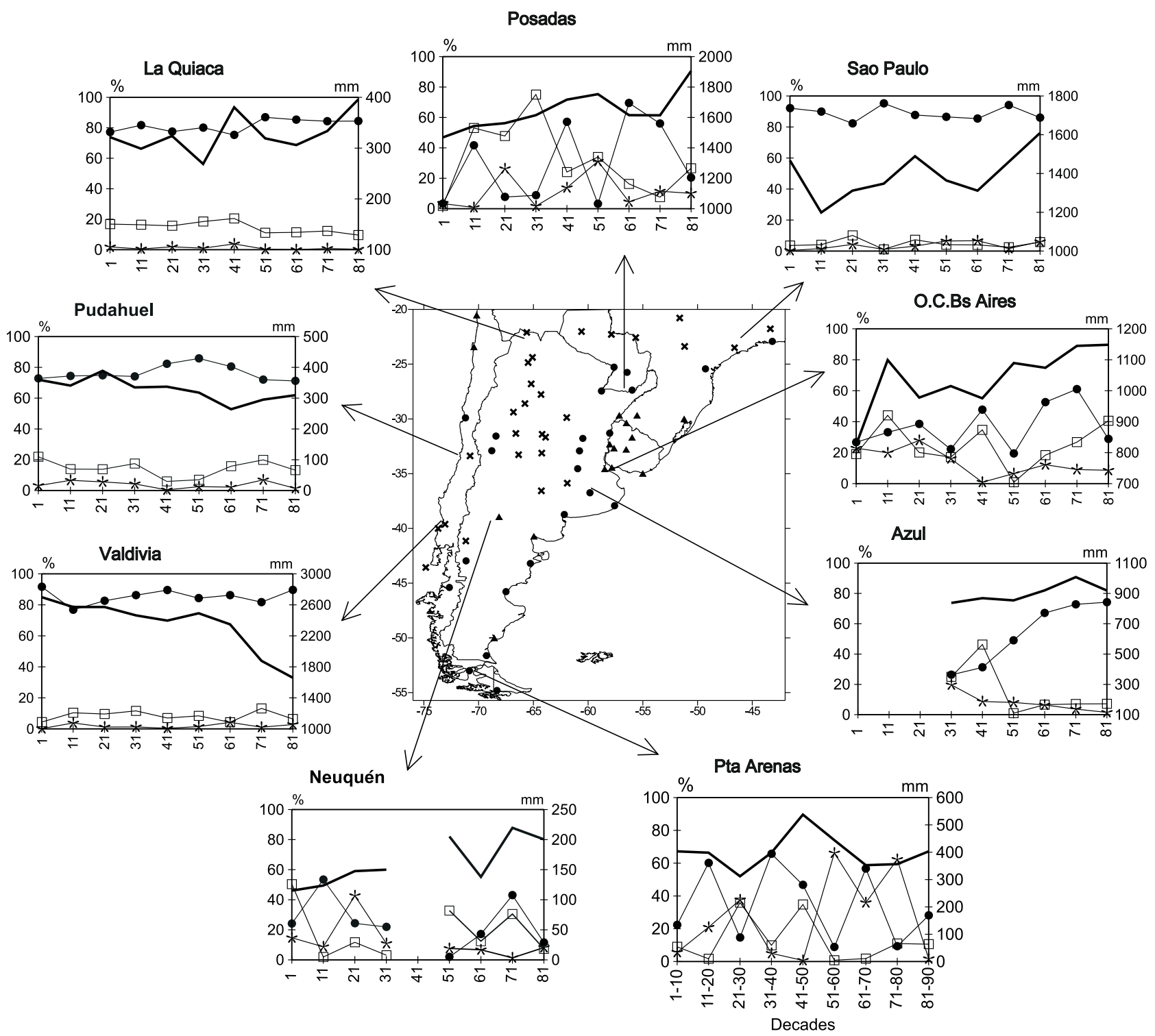

Fig. 6. Decadal march of variance explained (\%) by the first 3 harmonics (first:- - ; second: $-\square-$; third: $*$-) for certain particular stations and decade-mean precipitation (in $\mathrm{mm}$ ) (-). Map: (x) stations where the variance explained by the annual wave is

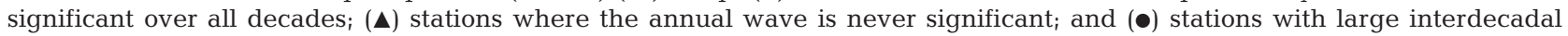
variability

maximum variance area, shows a decay in decadal annual precipitation over time. This low-frequency variability is not significant. There is a $10 \%$ increase in percentage in the annual cycle from 1941-50 until 1961-70. This inter-decadal variability may also be observed, although in the reverse direction, in the second harmonic percentage. Valdivia, located in the south, shows a decrease in total annual precipitation, from 2760 to $1680 \mathrm{~mm}$ (Fig. 6). This negative trend is mainly due to the months with maximum precipitation (May to July), decreasing from about $500 \mathrm{~mm} \mathrm{mo}^{-1}$ in $1901-10$ to $280 \mathrm{~mm} \mathrm{mo}^{-1}$ in $1981-90$. At this station, the total amount decreases, but the variance explained by the first harmonic is always significant; that is to say, the winter precipitation regime does not vary over the decades. In a study carried out by Hoffmann et al. (1997) for temperatures at Argentine stations, it was found that annual temperatures increase over the decades more significantly at stations located in southern Patagonia. This might result in a decrease in baroclinicity and less precipitation over the region under study, windward to the Andes. The same decreasing rainfall trend has been observed over southwestern Australia, and is associated with changes in local atmospheric circulation patterns (Allan \& Haylock 1993). These authors suggested that the observed climatic changes apparently result from a modulation of mid-latitude frontal systems, which could be applied 
also to SSA. In other papers (e.g., Hurrel \& van Loon 1993) a description was made of a circulation change over the southern hemisphere between 1971-80 and 1981-90, which could be one of the causes of the aforementioned decreasing precipitation values and change in rain-producing circumstances.

Returning to type-1 stations located at the centre of the northwestern Argentine maximum, the first harmonic is $99 \%$ significant over all decades, but there is some interesting decadal variability. La Quiaca shows a jump in the decadal amount of precipitation in 1941-50 (Fig. 6). In 1951, the percentage explained by the first harmonic begins to increase and that by the second one decreases. These changes are due to changes in the relationship between summer and winter precipitation; an extremely high Summer precipitation results in a less significant first harmonic, since in harmonic analysis such an increase corresponds to a greater amplitude of the second harmonic (Hsu \& Wallace 1976). After and before this decade, the regime has 2 clearly different shapes. At the same latitude, conditions at São Paulo show a different behaviour: a slight increase in total precipitation has occurred, particularly since 1961, but the precipitation regime remains unchanged for the whole century.

Type-2 stations, where the first harmonic has never been significant, are concentrated in 2 regions: the largest one over Uruguay and the eastern limit of Argentina, and the other over northern Patagonia. These 2 regions, as was already remarked, have a completely different regime precipitation. Concerning the former region, Observatorio Central Buenos Aires (O.C. Bs Aires) shows a positive trend in total annual precipitation (Fig. 6). The annual regime shows 2 peaks and is represented by different kinds of regimes throughout the decades, even though this harmonic is not significant. The relevance of the first harmonic varies; it shows an increase through the decades and is the main component, except for the second and last decades. The second harmonic starts with approximately zero relevance in 1951-60 and increases to the point of becoming the main harmonic in 1981-90, as in 1911-20.

Neuquén is located in northern Patagonia, where the importance of the first harmonic is always low (Fig. 6). Though data from 1 of the decades are missing, the total annual precipitation shows a positive trend and one of the most variable regimes: the relevance of the first harmonic changes from decade to decade but never becomes significant. Its precipitation regime has the same characteristics as the temperature regime, which shows the lowest persistence of warm and cold spells among all Argentine stations indicating a high variability in the persistence of synoptic systems (Rusticucci \& Vargas 1995a).
The group of stations located in transition areas (type-3) shows changing precipitation regimes through the decades, these being precisely the cases for which the first harmonic was significant in certain decades. Posadas shows the same positive trend in total annual precipitation corresponding to all stations located in northeastern Argentina and southern Brazil (Fig. 6). Its regime has changed from a second-harmonic regime in the period 1911-40 to a first-harmonic regime in 1961-80, a fact that highlights the displacement in the East-West direction of the line of $50 \%$ explained variance corresponding to the first harmonic (Fig. 5). In 1931-40, the second harmonic is as significant as the first in 1961-70. Such an increase in annual precipitation at Posadas is consistent with a simultaneous increase in the magnitude of sea-surface temperature anomalies in the Pacific Equatorial (Ropelewski \& Halpert 1987, Genta et al. 1998).

Azul, located at the centre of the province of Buenos Aires, shows a positive trend in the variance percentage explained by the first harmonic, which indicates a progressive change in the annual precipitation regime that becomes significant in later decades (from 1961 onwards). This increase of the variance explained by the first harmonic may be associated with a positive January (rainy month) trend shown in Penalba \& Vargas (1996). This area shows a clear climatic change, at least as far as annual precipitation is concerned, since it has changed in recent decades to a precipitation pattern with a strong first harmonic and this regime has persisted.

To the south, at Punta Arenas, total annual precipitation is low, about $500 \mathrm{~mm}$, with an increase in 1941-50. The first harmonic shows high variability, being significant in some decades. After the 1950s, the mechanisms that produce precipitation over this station changed into a regime dominated by the third harmonic in the 1951-60 and 1971-80 periods. At these stations, a change in the precipitation regime may be observed from the 1950s onwards. This period coincides with the one described by Castañeda \& Barros (1994) as showing the maximum trend over Argentina.

Therefore, it may be concluded that from the beginning of the century the variability in precipitation regime over SSA has not been uniform, showing areas with different inter-decadal variability; there have been jumps in the precipitation amount over northwestern Argentina, a remarkable increase in the influence of the first harmonic over the central-eastern region, no noticeable change over Chile, and alternating characteristics of the precipitation regime in other regions.

It is therefore reasonable to conclude that if there has been a possible climatic change over the last decades it might be clearly located over central-eastern SSA and might be attributed to a precipitation increase during 
summer months that has generated a change in the precipitation regime persisting over recent decades. From 1951-60 onwards, some stations show changes in the form of precipitation as well as an increase in its values.

\subsection{Temperature-precipitation relationship}

Several authors attempted to find a relationship between precipitation and temperature for different purposes. Evidence has been reported that there is a relationship between these variables in different regions of the world, as in the aforementioned cases of Australia and the USA. The connection between these climatic variables has not been evaluated previously for SSA.

First, the temporal evolution of the decadal thermal field over the entire century was analysed (results not shown). Beginning the analysis in 1901-10, the first $30 \mathrm{yr}$ show neutral to slightly positive temperature anomalies, and the following decades differ from one another, showing a large inter-decadal spatial variation of temperature. 1971-80 shows the most extended negative temperature anomaly area, which occupies nearly the entire region studied. 1981-90 shows positive temperature anomalies through the entire region, except for an important negative anomaly nucleus $\left(-1^{\circ} \mathrm{C}\right)$ located to the north of the central part of the region under study, and another one, not so relevant, over the south of central Chile.

In order to summarise temperature variability throughout the century, Fig. 7 shows differences between the average decadal temperature for 1981-90 and that of 1901-10. As may be seen, spatial variability

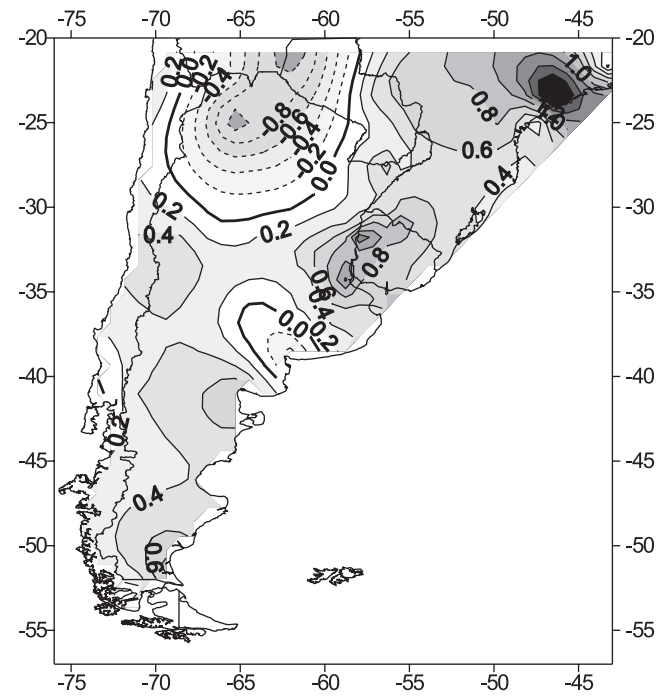

Fig. 7. Differences in decadal mean temperatures (in ${ }^{\circ} \mathrm{C}$ ) between 1981-90 and 1901-10 is great indeed. The widest differences occur in northern SSA, probably due to higher temperature values, and have opposite sign in the east and the west. Over Argentina (between 65 and $70^{\circ} \mathrm{W}$, approximately), a decrease in the north-south gradient may be observed, derived from a significant temperature increase at stations in the south of the country (already reported by Hoffmann et al. 1997) and an opposite decrease in temperature in the north. Regarding possible global warming, these results show that there is no regional homogeneity in SSA. There are different trends depending on the region, as has been previously reported for some locations, for example, by Morel (1990) and Rosenblüth et al. (1997).

Due to the previously studied wide spatial variability in temperature, a search is carried out for the warmest and coldest decades throughout SSA analysing $10 \mathrm{yr}$ running means. The period 1943-52 is the warmest decade for the whole region during the longest study period (1901-90), showing anomalies that exceed $0.2^{\circ} \mathrm{C}$ throughout the entire region, and a maximum of $0.8^{\circ} \mathrm{C}$ in northeastern Argentina (Fig. 8). Two extremely cold decades, 1955-64 and 1966-75, must be considered with regard to the coldest period, depending on the region; maximum cooling occurred during 1966-75, which shows areas with negative anomaly values below $-0.6^{\circ} \mathrm{C}$. These extreme decades will be examined so as to analyse the rainfall pattern during opposite thermal conditions and determine whether the relationship between the variables involved depends on temperature values.

Correlation coefficients between monthly precipitation and temperature were calculated in 2 ways: (1) by spatial analysis (all possible month pairs for each decade) in order to study the precipitation-temperature annual regime and how this relationship changes over time, and (2) by temporal (year-to-year) analysis for each month throughout the whole period, in order to increase our understanding of seasonal climatic variability in the region.

\subsubsection{Spatial analysis}

The patterns of decadal correlation between the series of monthly precipitation and temperature (January to December, years 1 to 10 for each decade) were calculated and the significance coefficient (95\%) was estimated for each station, due to differences in record length. Over all the decades involved, these patterns show 2 centres of maximum correlation corresponding to the precipitation regime: negative correlation (winter precipitation) over Chile and positive correlation (summer precipitation) over northwestern Argentina. To analyse the rainfall pattern during opposite thermal 
1943-52

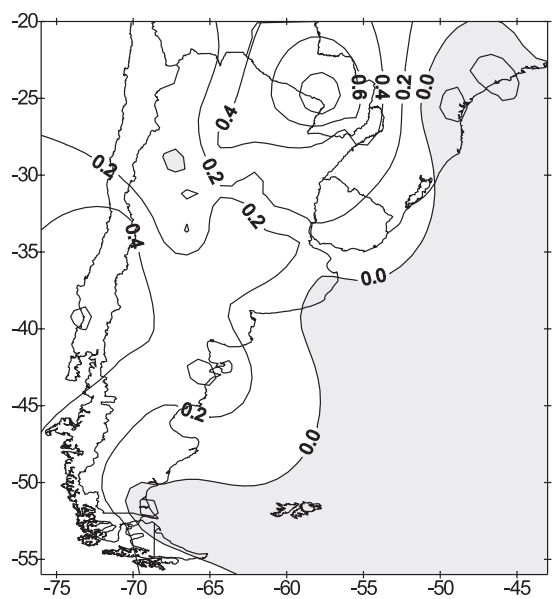

1955-64

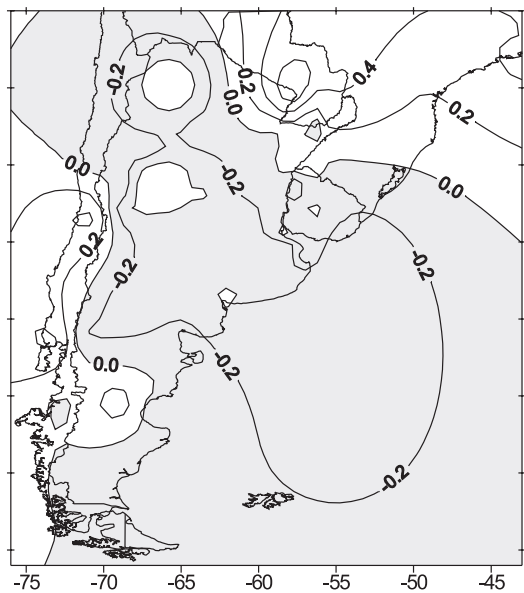

1966-75

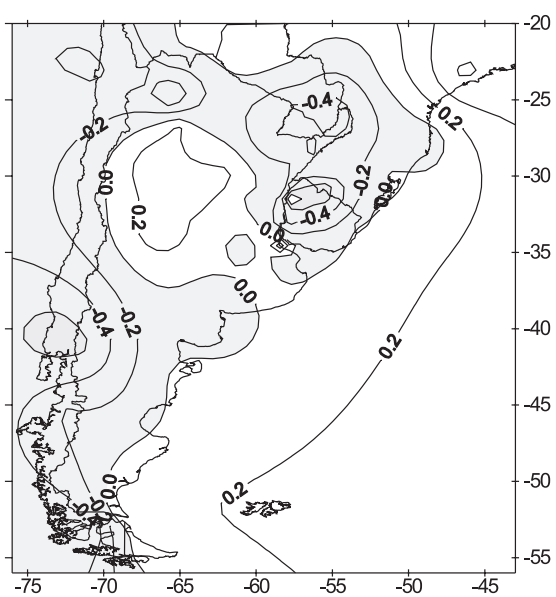

Fig. 8. Anomalies from the long-term (1901-90) decadal mean temperature $\left({ }^{\circ} \mathrm{C}\right)$ in the warmest (1943-52) and coldest (1966-75 and 1955-64) decades. Anomalies corresponding to stations in Uruguay are calculated from the 1951-90 mean. Shaded: negative anomalies

1943-52

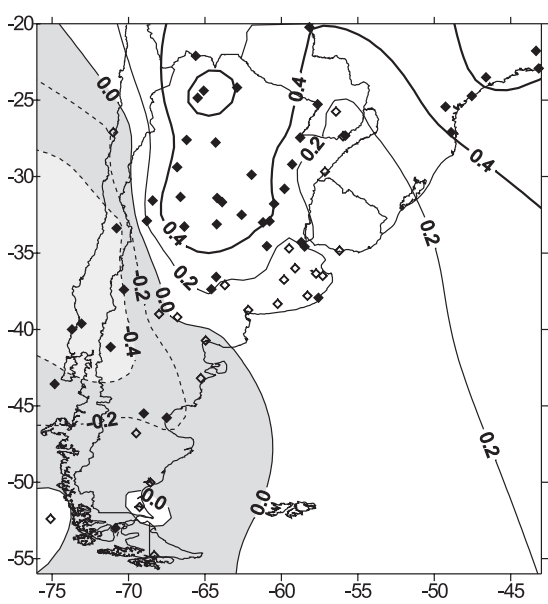

$1955-64$

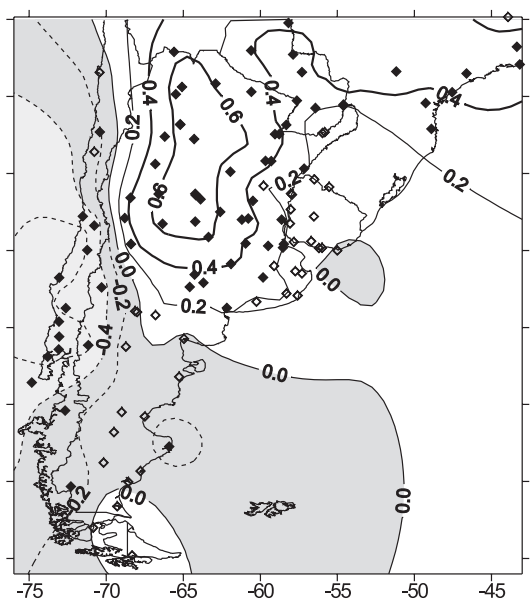

1966-75

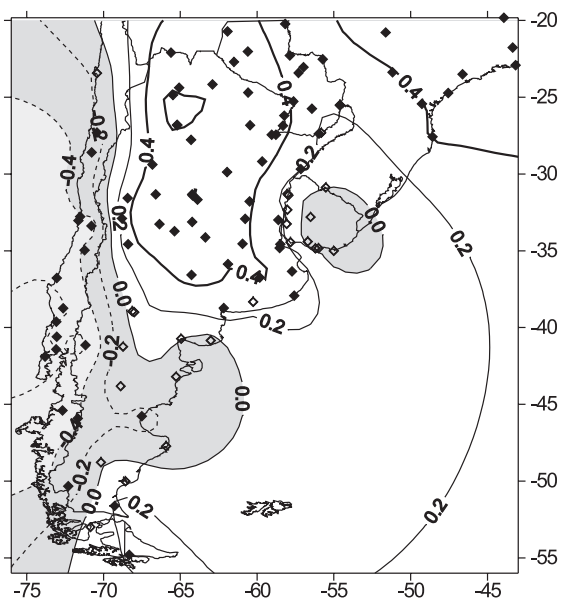

Fig. 9. Patterns of decadal correlation between monthly precipitation and temperature for the warmest (1943-52) and coldest (1966-75 and 1955-64) decades. Stations with significant coefficients are indicated by a solid rather than an open symbol. Shaded: negative correlation

conditions and determine whether the relationship between the variables involved depends on temperature values, correlation patterns in decades of extreme temperature were considered. Precipitation-temperature correlation patterns in the coldest and warmest decades indicate that, in central-northern Argentina and central Chile, the positive correlation in the warmer 1943-52 period is generally lower than the correlation in the colder $1955-64$ or $1966-75$ periods (Fig. 9). The weakest negative correlation coefficients over Chile and the highest positive correlation in NW are found in colder regions for 1966-75. These differ- ences among correlation patterns are apparently due not only to the mean temperature but also to the mean annual temperature variation; also to be seen is a concentration of rainfall in the months of highest precipitation values in coldest periods, since in this case the correlation coefficient indicates how coherent temperature and precipitation first harmonics waves are.

With respect to the northern hemisphere, Zhang et al. (1997), among others, concluded that the changes occurring in 1976-77 reflect the dominant pattern of interdecadal variability rather than the inter-annual scale, since the structure apparent in the main compo- 
nents of SST in this scale is the same for changes recorded before and after 1976-77 that period.

The question arises whether this relationship between temperature and precipitation has changed since 1976. 1976-85 temperature anomalies show a pattern with negative anomalies located in northern Argentina, southern Brazil and Chile, having a smaller negative area than 1966-75, shown in Fig. 8. The main change in the correlation pattern between 1976-85 and 1966-75 occurs in northeast Argentina and central-eastern SSA, where the correlation becomes significant (result not shown). This supports the idea that maximum correlations accompany maximum negative temperature anomalies, especially in northwestern and central Argentina and central Chile, where precipitation has a definite annual cycle. Because there are positive or zero temperature anomalies over the province of Buenos Aires, as was the case in 1966-75, the increase in correlation over this province and northwards might be related mainly to a change in circulation in this area, rather than to the temperature value; therefore, from this point of view, there has been a noticeable change in atmospheric conditions in this region since 1976-77.

Results of the warmest/coldest decades should be taken into consideration for the analysis of global warming over the region. It seems that on the monthly scale both variables lose some correlation during warmer periods, and precipitation variability forecasts relative to a possible global warming should therefore take into account that the form of the annual cycle is altered in warmer decades.

\subsubsection{Temporal year-to-year analysis}

To complete the relationship between monthly precipitation and temperature, the correlation between both variables for each month of the year and for the entire period was calculated, and the correlation significance at the $95 \%$ level was determined for each station. Geographic patterns of precipitation-temperature correlation vary from month to month (Fig. 10).

During the warmest months (December to April), there is an inverse relationship between precipitation and temperature over most of the region, and a large area with a significant correlation. That is, warmer summers are associated with low precipitation, mainly in northeast and central-western Argentina, southern Chile, and Paraguay. The other combination, colder and wetter, could be explained by extremely cold temperatures in summer due to the frequent passage of cold fronts over central Argentina that produce rainfall. Hence, assuming that monthly data reflect the incidence of daily synoptic situations, these correlation patterns, showing that colder summers result in more precipitation, confirm the results of Rusticucci \& Vargas (1995b), which coincided with those of Power et al. (1999), and Zhao \& Khalil (1993), who also arrived at the same order of magnitude described in the present work. It should be noted that the values of all correlation coefficients herein computed over detrended series are lower than the corresponding ones for untreated series.

Winter (June to August) correlation shows a weak positive pattern to the west of $65^{\circ} \mathrm{W}$, possibly due to the fact that the stratiform cloud cover produces a higher minimum temperature. Another positive centre, though small, appears on the Chilean coast and becomes larger in May. This centre is related to migratory cyclones, which give rise to northerly winds in this region. On the southern coast of Patagonia, the prevailing winds are the southeasterlies, cold and wet, giving rise to precipitation.

During autumn and spring months, correlation is positive in the eastern part of Argentina and Paraguay. That is, warmer-than-normal months are associated with higher precipitation, due to the influence of northeastern advection, especially in May and October. This is in full agreement with the mechanism of maximum precipitation in this area, which is mainly the result of cyclogenesis.

In the west of central Argentina, a region of negative correlation is observed throughout the year. It is a region of semi-arid climate and scarce precipitation throughout the whole year and where rainfall is due to incoming cold air from the Atlantic interacting with the orographic relief at the centre of the region under study.

\section{DISCUSSION}

The purpose of this study was to analyse the interdecadal variability of the annual precipitation regime over South America south of $20^{\circ} \mathrm{S}$, with respect to the low-frequency variability shown by annual values, and to examine the relationship between precipitation variability and the variability observed in the temperature regime.

During the period analysed, the precipitation annual wave (first harmonic) represents the precipitation regime over most of the region studied, with 2 centres of maximum explained variance having opposite phases: summer in northwestern Argentina and winter in southern Chile. Towards the eastern part of the region, the semi-annual wave (second harmonic) becomes the prevailing one, with a maximum centre of $50 \%$ explained variance.

Interdecadal variations of the precipitation regime show different patterns. Over NW Argentina, there is 

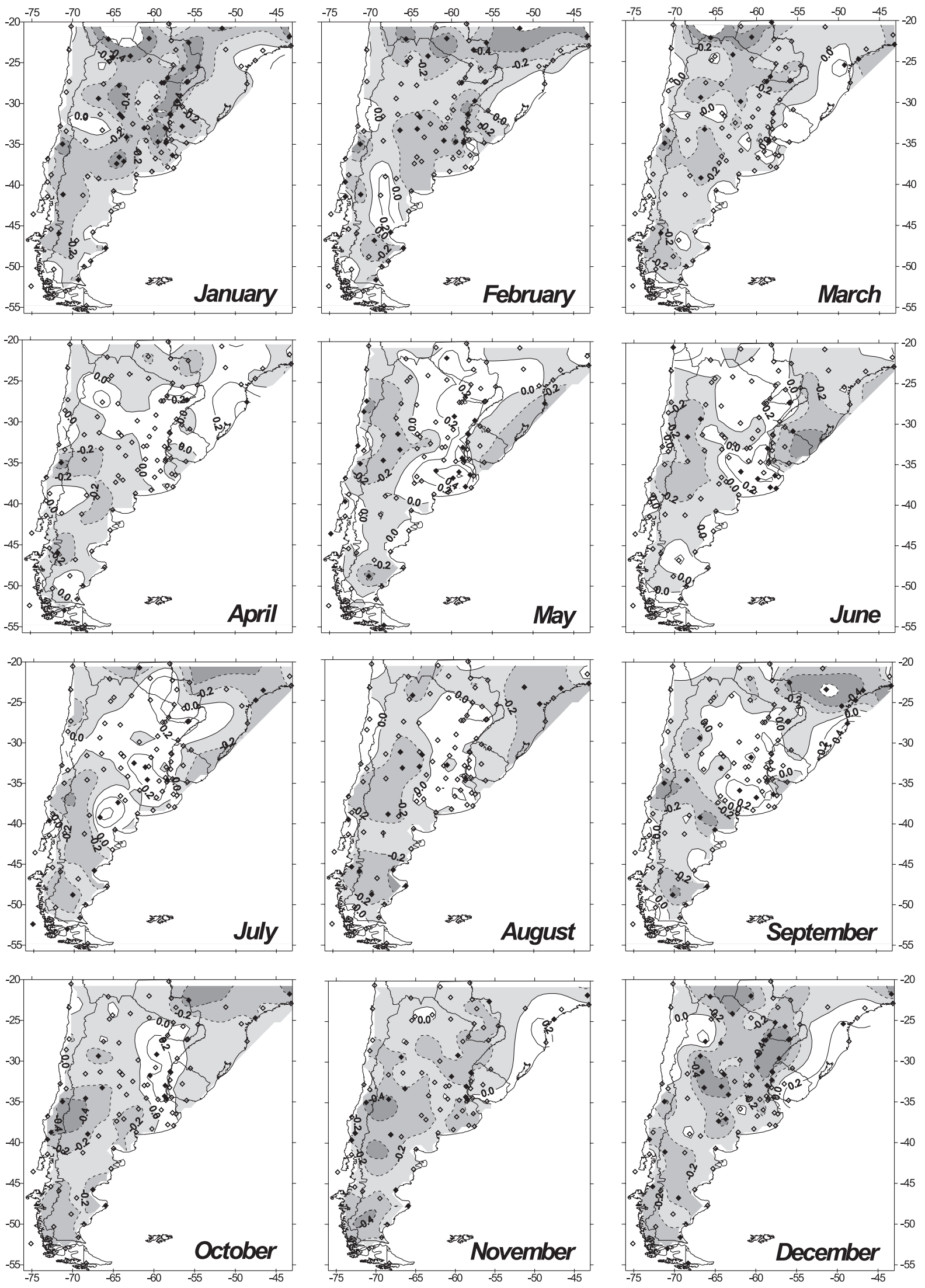

Fig. 10. Monthly correlation patterns over 1901-90. Significance: see Fig. 9. Shaded: negative correlation 
an indication of a jump in the regime according to annual values; over central-eastern SSA there is a significant positive trend in the importance of the first harmonic, indicative of a long-term climate change. There is no change in the shape of the precipitation regime over central Chile, indicative of the same precipitation mechanisms although lower in intensity in the south. In climate-transition regions, between the centres of maximum and minimum relevance of the first harmonic, the first harmonic alternates, representing the highest climate variability in SSA.

The correlation between precipitation and temperature regimes shows decadal differences depending on temperature values in regions with an annually shaped precipitation regime. In general, the lower the mean decadal temperatures, the higher the correlation between waves, i.e., precipitation concentrates in summer in the northwest (the same holds for Chile in winter) during the coldest periods. These differences among correlation patterns seem to be due not only to the mean temperature but also to the mean annual temperature and precipitation variations. Over Buenos Aires, the intensified relationship along the decades seems to be related to other causes, such as changes in circulation, since it does not depend apparently on temperature values.

The cross-correlation of detrended monthly series quantifies some of the precipitation mechanisms. During summer there is an inverse relationship between precipitation and temperature over most of the region. That is, warmer summers tend to have lower summer precipitation. The opposite could result from higher cloudiness, related or not with the more frequent passage of cold fronts, depending on the region considered.

During the remaining months of the year (April to October), the correlation pattern has a region with positive values in the Argentine eastern zone (the same area that shows the most significant negative coefficients in summer), supporting the hypothesis that warm and wet air masses are needed to produce rainfall. Over the central-western region there is a strong negative relationship which shows that precipitation is related to cold air masses. Therefore, the precipitation model has opposite signs in the east and the west.

In Chile, the correlation is always positive and significant, especially in the months of rainfall (May to September) clearly showing that warm months are related to precipitation mechanisms.

Acknowledgements. The authors wish to express their gratitude to Dr Walter Vargas and Dr Juan Minetti for their useful comments on the results of this work, to Prof. Sultan Hameed for his valuable suggestions during the writing of this paper, and to the anonymous referees, who enhanced this work with their suggestions. Support for carrying out this work was provided by the University of Buenos Aires through Grant TW06 and by Consejo Nacional de Investigaciones Centificas y Técnicas (CONICET) through Grant 4557.

\section{LITERATURE CITED}

Allan R, Haylock M (1993) Circulation features associated with the winter rainfall decrease in Southern Australia. J Clim 6:1356-1367

Castañeda M, Barros V (1994) Las tendencias de la precipitación en el cono sur de América al este de los Andes. Meteorológica XIX:23-32

Cayan D, Dettinger M, Diaz H, Graham N (1998) Decadal variability of precipitation over Western North America. J Clim 11:3148-3166

Chen TC, Yen M (1997) Interdecadal variation of the Southern Hemisphere circulations. J Clim 10:805-812

Compagnucci R, Salles M (1997) Surface pressure patterns during the year over Southern South America. Int J Climatol 17:635-653

Diaz AF, Studzinski CD, Mechoso CR (1998) Relationships between precipitation anomalies in Uruguay and Southern Brazil and sea surface temperatures in the Pacific and Atlantic Oceans. J Clim 11:251-271

Finkelstein P, Truppi L (1991) Spatial distribution of precipitation seasonality in the United States. J Clim 4:373-385

Genta J, Perez-Iribarren G, Mechoso C (1998) A recent increasing trend in the streamflow of rivers in Southeastern South America. J Clim 11:2858-2862

Hoffmann J (1975) Atlas climático de América del Sur. WMO, Unesco, Geneva

Hoffmann J, Nuñez S, Vargas W (1997) Temperature, humidity and precipitation variations in Argentina and the adjacent Sub-Antarctic region during the present century. Meteorol Z N F 6:3-11

Hsu C, Wallace JM (1976) The global distribution of the annual and semiannual cycles in precipitation. Mon Weather Rev 9:1093-1101

Hurrel J, van Loon H (1994) A modulation of the atmospheric annual cycle in the Southern Hemisphere. Tellus 46A: 325-338

Kirkyla K, Hameed S (1989) Harmonic analysis of the seasonal cycle in precipitation over the United States: a Comparison between observations and a general circulation model. J Clim 2:1463-1475

Krepper C, Scian B, Pierini J (1989) Time and space variability of rainfall in Central-East Argentina. J Clim 2:39-47

Minetti J, Vargas W (1983) Fluctuaciones de la temperatura media en Sudamérica y Hemisferio Sur en el período: 1941-60. Meteorológica XIV:225-235

Minetti J, Vargas W (1997) Trends and jumps in the annual precipitation in South America south of the $15^{\circ} \mathrm{S}$. Atmósfera 11:205-221

Morel P (1990) Global climate change. WCRP-WMO, Geneva and ICSU, Paris

Penalba O, Vargas W (1996) Climatology of monthly and annual rainfall in Buenos Aires, Argentina. Meteorol Appl $3: 275-282$

Pittock AB (1980a) Patterns of climatic variation in Argentina and Chile. I. Precipitation 1931-60. Mon Weather Rev 108: $1347-1361$

Pittock AB (1980b) Patterns of climatic variation in Argentina and Chile. II. Temperature 1931-60. Mon Weather Rev 108:1362-1378

Poblete A, Minetti J, Sierra E (1989) La influencia del régimen 
hídrico andino-puneño en el Oasis del Noroeste Argentino y Cuyo. Geofísica 30:137-149

Power S, Tseitkin F, Mehta V, Lavery B, Torok S, Holbrook N (1999) Decadal climate variability in Australia during the twentieth Century. Int J Climatol 19:169-184

Prohaska F (1952) Regímenes estacionales de precipitación de Sudamérica y mares vecinos (desde $15^{\circ} \mathrm{S}$ hasta Antártida). Meteoros II:66-100

Prohaska F (1976) The climate of Argentina, Paraguay and Uruguay. In: Schwerdtfeger W (ed) Climates of Central and South America. World Survey of Climatology, Vol 12. Elsevier Scientific Publishing Company, Amsterdam, p 13-72

Ropelewski CH, Halpert S (1987) Global and regional precipitation patterns associated with the El Niño/Southern Oscillation. Mon Weather Rev 115:1606-1626

Rosenblüth B, Fuenzalida H, Aceituno P (1997) Recent temperature variations in Southern South America. Int J Climatol 17:67-86

Rusticucci M, Vargas W (1995a) Changes in temperature anomalies persistence over Argentina. Proc 6th Symp on Global Change Studies. American Meteorol Society, Dallas, TX, p 101-102

Editorial responsibility: Mike Hulme, Norwich, United Kingdom
Rusticucci M, Vargas W (1995b) Synoptic situations related to spells of extreme temperatures over Argentina. Meteorol Appl 2:291-300

Scott C, Shulman M (1979) An areal and temporal analysis of precipitation in the northeastern United States. J Appl Meteorol 18:627-633

Siegel A (1980) Testing for periodicity in a time series. J Am Stat Assoc June: 345-348

Van Loon H, Kidson J, Mullan A (1993) Decadal variation of the annual cycle in the Australian dataset. J Clim 6: $1227-1231$

Vargas W, Penalba O (1985) Análisis de la estabilidad de estimaciones estadísticas en series climáticas de Buenos Aires. Meteorológica 15(2):41-50

Vargas W, Penalba O (1986) Análisis del posible efecto de la ciudad en la serie de precipitación mensual de Buenos Aires. Geoacta 13:217-227

Zhang J, Wallace J, Battisti D (1997) ENSO like interdecadal variability: 1900-93. J Clim 10:1004-1020

Zhao W, Khalil M (1993) The relationship between precipitation and temperature over the contiguous United States. J Clim 6:1232-1236

Submitted: July 26, 1999; Accepted: March 10, 2000 Proofs received from author(s): August 28, 2000 